\title{
Tangence
}

\section{Une écriture omnibus (Les fleurs, de Christian Gailly)}

\section{Éric Gauvin}

Numéro 49, décembre 1995

Les littératures francophones de l’Afrique et des Antilles

URI : https://id.erudit.org/iderudit/025884ar

DOI : https://doi.org/10.7202/025884ar

Aller au sommaire du numéro

Éditeur(s)

Tangence

ISSN

0226-9554 (imprimé)

1710-0305 (numérique)

Découvrir la revue

Citer ce compte rendu

Gauvin, É. (1995). Compte rendu de [Une écriture omnibus (Les fleurs, de Christian Gailly)]. Tangence, (49), 126-128. https://doi.org/10.7202/025884ar d'utilisation que vous pouvez consulter en ligne.

https://apropos.erudit.org/fr/usagers/politique-dutilisation/ 


\section{Une écriture omnibus \\ Christian Gailly, Les fleurs, Paris, Minuit, 1993, 92 p.}

[...] le prochain train est omnibus, comme ma façon d'écrire, normale.

Christian Gailly, Les fleurs

Je ne peux aimer que ceux qui ont une langue incertaine; et ceux qui me plaisent je veux rendre leur langue incertaine.

Peter Handke, L'bistoire du crayon ${ }^{1}$

Étrange chassé-croisé que celui auquel nous convie Christian Gailly. Tout se résume, pour ainsi dire, à des allées et venues: celles des deux protagonistes, des êtres plutôt perturbés, et celles, assez inusitées, d'un écrivain qui tergiverse en ne se prenant pas au sérieux. Le moins que l'on puisse dire c'est que l'auteur prend un malin plaisir à multipler les interventions, ce qui donne un tour comique à son roman par ailleurs fort troublant.

Il y a d'abord cette femme anonyme qu'une maladie - on songe à un cancer - rend distraite, puis un homme timoré dénommé Paul Bast qui doit visiter un ami dans un quartier de Paris. Tous deux ne se connaissent pas, mais puisqu'ils se dirigent vers un même lieu, ils échappent, l'espace d'un moment, au chaos, au mouvement erratique des passants: "Les mêmes gens, sauf qu'ils vont dans l'autre sens, c'est toujours troublant, c'est déjà troublant de voyager avec des gens qui ne vont pas où vous allez mais quand ils vont dans l'autre sens, c'est encore plus troublant, on a envie par-dessus la voie de leur demander qui ils sont, où ils vont" (p. 39). Cependant cette similitude entre les deux parcours suscite une commotion plus intime, plus périlleuse encore, comme s'il y avait intrusion et que ni la femme ni l'homme ne pourraient sortir indemnes d'une ultime rencontre.

1 Peter Handke, Lbistoire du crayon, Paris, Gallimard, coll. "Du monde entier ", 1987, p. 99. 
Avant de voir son médecin qui lui communiquera les résultats d'un examen, la femme doit - tel que le précise la quatrième de couverture - remplacer la cartouche de son stylo, action anodine qui permet toutefois à Gailly de décrire avec justesse toutes les incidences qu'un désarroi réel a sur ces menus gestes apparemment insignifiants qui composent la vie quotidienne. La femme ne sait que répondre à la vendeuse qui lui pose la question d'usage: "Ce que je désire. Eh bien. Voilà que je ne sais plus ce que je désire. Probablement rien. Qu'est-ce que je peux désirer maintenant? Rien. Voilà, c'est ça rien" (p. 10). Il y a cette mémoire qui chancelle tandis qu'une perpétuelle impression de déjà-vu l'incommode. Ce lisant, on discerne le déséquilibre sous ses formes les plus ténues, mais peut-être les plus authentiques.

Quant à Paul Bast, il est bouleversé par le rouge incandescent de ces fleurs qui couvrent la jupe de la femme; cette couleur évoque dans son esprit un événement marquant dont la nature demeure ambiguë :

Je lui dirais voyez-vous, le rouge des fleurs de votre jupe, ça me rappelle un premier sang. Non. Si. Perpétré en plein été dans un grand champ, clairsemé, non, parsemé de fleurs, ça faisait des taches, de larges taches, non des plaques, oui, par vagues, et la brise était tiède, non, le vent soufflait en rafales chaudes, non plus, enfin bref, sous les grands coups de zeph tout le champ se vangoghisait. (p. 75)

Le langage n'est que réticence. L'homme velléitaire s'interdit de dire, oubliant qu'ainsi il s'expose à l'implacabilité des pensées: "Il sent dans sa tête la pression des pensées. Les pensées poussent au portillon de la pensée. Elles ont envie de se faire penser par lui. Elles exigent qu'il les pense" (p. 59). Si la situation dégénère, c'est bel et bien à cause de ce mutisme, de ce désir qui est tu. En effet, lorsque Paul Bast tente enfin une approche, la femme craint qu'il lui fasse du mal, dès lors elle réagit vivement et s'ensuit un violent quiproquo. Cependant, la fin laisse croire que, sous "la pointe feutre extra-fine" de Gailly, le hasard fait bien les choses.

Tout de même, rien là de réjouissant, pensez-vous. Or, détrompez-vous, l'auteur est plutôt facétieux. Son humour sans émousser le climat d'étrangeté qu'il met en ouvre - dédramatise le tout et révèle sans fard la difficulté d'écrire, de trouver les mots justes. "Sourire de la jeune fille, Ahanchée. Non. Enhan- 
chée. Non plus. Décidément le mot n'existe pas. Appuyée de la hanche à la caisse. Avec une grâce. Oui, bon, laisse tomber" (p. 21). Cette langue incertaine et hésitante amuse; on sourit aussi lorsque l'auteur laisse libre cours à ce doute qui le tenaille: "C'est toujours quand j'ai fini d'écrire que me viennent les idées intéressantes, ce qui fait que je suis réduit à écrire des histoires comme celle-ci, pas intéressante, enfin on verra. (p. 23). L'aveu étonne, n'est-ce pas?

Pour ce ton bon enfant que l'on marie adroitement à une histoire trouble, il faut vraiment lire Les fleurs et non pas faire semblant comme cette femme qui feignait de lire un livre qui ne l'intéressait pas pour qu'on s'intéresse à elle (p. 35).

Éric Gauvin 